\title{
त्री \\ O controle de características genéticas humanas através da institucionalização de práticas socioculturais eugênicas
}

Valdeir DEL ConT

\begin{abstract}
象
RESUMO

Uma das características do movimento eugênico foi a formação de uma estrutura institucionalizada. Tal característica inicia-se com Francis Galton, mas é nos Estados Unidos que adquire a formatação institucional que servirá de modelo para as várias iniciativas eugênicas em outras partes do mundo. Neste texto, pretendemos analisar algumas condições que contribuíram para a eugenia ser apresentada como uma proposta científica de controle social de traços ou características consideradas geneticamente determinadas.
\end{abstract}

PaLAVRAS-GhaVe • Eugenia. Instituições eugênicas. Controle social de características genéticas. Raça. Melhoramento racial.

Nos meios acadêmicos, midiáticos e diversos outros, o termo eugenia está relacionado à ideia de um procedimento politicamente incorreto, cientificamente deturpado e eivado de preconceitos. Todavia, por várias décadas, do final do século xix até a década de 1930, importantes e respeitáveis representantes de vários campos científicos incorporaram a eugenia em suas preocupações no que dizia respeito à melhoria das condições sociais, ao combate de condições produtoras de pobreza e de miséria, ao incremento das condições de saúde da população e às reformas legais e educacionais (cf. Goddard, 1912; U.S. Suprem Court, 1927; Mehler, 1988; Winfield, 2004).

Com efeito, os proponentes da eugenia procuraram desenvolvê-la desde o início em duas frentes interligadas. Primeiramente, como um programa de investigação científica, através de esforços conjugados provenientes da matemática, da estatística, da biologia e da antropologia com o firme propósito de fornecer uma teoria que compreendesse os mecanismos responsáveis pelo fenômeno da hereditariedade humana (cf. Cowan, 1972; Paul, 1995; Kenna, 1964). Em segundo lugar, baseados na seleção 
artificial, eles pretendiam criar instituições que pudessem fornecer instrumentos e políticas para o controle da hereditariedade humana por intermédio da reprodução orientada pelos princípios eugênicos (cf. Davenport, 1909, 1972 [1911]).

Os ideais eugênicos, de modo particular a preocupação com a qualidade racial dos indivíduos, eram temas correntes na Europa naquela época, e influenciavam fortemente vários estudos que se estendiam desde investigações anatômicas e fisiológicas (cf. Darmon, 1991, p. 20-25), chegando até justificativas imperialistas baseadas na ideia da superioridade racial e civilizatória do homem europeu (cf. Lorimer, 1996, p. 20). Mas a naturalização dos problemas sociais, a atribuição de culpa ao miserável por sua própria miséria, ou à condição biológica do criminoso pelo crime, de modo algum era consenso entre os pensadores da época. Marx e Engels, por exemplo, chamavam a atenção das massas e dos intelectuais para os fatores sociais, políticos e econômicos do capitalismo industrial no tocante ao estabelecimento das condições nas quais os trabalhadores viviam. Também Lacassagne, entre outros, a partir de uma perspectiva sociológica, procurava contestar as ideias de Cezare Lombroso acerca de o crime ser consequência da existência de disposições internas nos indivíduos, levandoos a uma existência criminosa (cf. Darmon, 1991, p. 91).

Contudo, mesmo com contundentes objeções, a tese de que as diferenças humanas decorreriam de disposições biológicas herdadas era aceita por muitos como cientificamente estabelecida (cf. Lorimer, 1996), o que fazia com que se tornasse imperioso o controle da proliferação dos traços degenerativos entre a população. A eugenia, como ciência destinada ao controle reprodutivo das especificidades hereditárias dos seres humanos, nasce, portanto, envolta em vários elementos dispersos, constituindo um campo de produção de saber em torno do qual gravitavam teorias raciológicas, determinismo biológico e técnicas de investigação antropométricas e craniométricas, com o firme propósito de determinar, discriminar e controlar a ocorrência de uma série de fenômenos que envolviam a proliferação de doenças, a prostituição, a criminalidade, a pobreza e, o que mais tarde se tornou o foco principal das medidas eugênicas, o déficit de inteligência (cf. Galton, 1887; Blanckaert, 2001; Madureira, 2003).

Todavia, a nossa intenção neste artigo é tão somente oferecer elementos que demonstrem que a força do projeto eugênico, nas primeiras décadas do século xx, se deveu ao processo de articulação de práticas que pretendiam oferecer ao movimento o status de empreendimento científico, através da criação de espaços institucionais interconectados que tinham como missão oferecer ao ideário eugênico, com seus laboratórios, metodologias e órgãos de identificação e discriminação dos traços hereditários considerados disgênicos, supostos conhecimentos científicos que subsidiassem políticas que visavam impedir a proliferação dos eugenicamente indesejáveis. 
Francis Galton (1822-1911), fundador da eugenia, concebeu-a apoiando-se na pressuposição de que as características comportamentais e intelectuais decorreriam de predisposições internas que os indivíduos transmitiriam aos seus descendentes através da reprodução (cf. Paul, 1995, p. 3o). Nesse sentido, ao cunhar o termo eugenics cuja etimologia remete ao conceito de bem nascido -, Galton assumia a posição de que o meio ambiente não era o responsável pelos traços ou características físicas, comportamentais e intelectuais distribuídos em um conjunto populacional. Para ele, essas características ou traços resultavam de disposições biológicas internas que se expandiam na população através da reprodução. Suas ideias, portanto, diziam respeito ao problema da transmissão de características dos progenitores para a prole, isto é, ao problema da herança (cf. Cont, 2008).

Francis Galton procurou dar à eugenia os contornos de uma abordagem que se pretendia científica, preocupada em compreender os mecanismos responsáveis pela hereditariedade. Todavia, no final do século xix, segundo Ernst Mayr, as teorias que se envolveram com o problema da hereditariedade eram fortemente especulativas (cf. Mayr, 1998, p. 701). A despeito de todas as dificuldades em se compreender os mecanismos envolvidos na transmissão das características, Galton tinha pelo menos duas ideias norteadoras para a sua ciência eugênica. Primeiro, que o meio não interferia na formação de características que seriam transmitidas para as próximas gerações, negando com isso a herança de características adquiridas (cf. Galton, 1872). Segundo, que os dados que subsidiariam tal ciência resultariam do registro e da análise estatística das características que os progenitores e seus ancestrais transmitiam à prole (cf. Cowan, 1972, p. 512). Para ele, ademais, a transmissão das características não se limitava apenas a aspectos físicos, mas também a habilidades e talentos intelectuais (cf. Galton, 1892, p. 6).

Baseando as suas ideias nos princípios da seleção natural de seu primo Charles Darwin, Galton defendia que a melhoria das condições gerais da sociedade, tanto das características das pessoas quanto das condições sociais, passava pela seleção artificial através de dispositivos legais e institucionais que pudessem orientar eugenicamente a reprodução humana (cf. Galton, 1904, p. 3-4). A proposta consistia, basicamente, em controlar a capacidade reprodutiva dos indivíduos através de orientação eugênica das uniões matrimoniais. Em outras palavras, através de medidas restritivas buscarse-ia favorecer uniões consideradas representativas das melhores características e impedir uniões que propagassem características consideradas responsáveis pela degradação das condições pessoais, familiares e sociais (cf. Castañeda, 2003, p. 911-3). 
Muito embora parecesse a Galton, em um primeiro momento, que direcionar a hereditariedade por intermédio dos princípios eugênicos era um modo eficiente de melhorar as características hereditárias humanas, em um segundo momento, contudo, ele passou a considerar que não seria uma tarefa fácil, pois além de ter que enfrentar as dificuldades da dinâmica das relações, que escapariam ao controle mais rigoroso, tal procedimento feriria os princípios de uma sociedade baseada nos valores democráticos (cf. Galton, 1908, cap. xxi).

Diante disso, Galton mudou significativamente seus propósitos de reforma social através do controle da hereditariedade humana. Se em um primeiro momento a sua proposta foi no sentido de controle efetivo da reprodução humana através da regulamentação das uniões conjugais, posteriormente Galton admitia que os esforços eugênicos deveriam ser no sentido de se estabelecer condições para que os indivíduos aderissem às práticas eugênicas por reconhecerem o seu valor moral e social (cf. Galton, 1908). Em sua opinião, as uniões orientadas eugenicamente deveriam depender muito mais da adesão de indivíduos conscientes de seu valor para o bem geral da humanidade, do que de algum tipo de controle externo. Portanto, para Galton, as relações eugenicamente orientadas configurariam muito mais uma obrigação moral e, até, um princípio religioso (cf. Galton, 1904; 1908).

Nos Estados Unidos da América a eugenia ultrapassou o sentido de controle social das uniões matrimoniais. Em um contexto marcado por crescente imigração e forte sentimento segregacionista, os eugenistas estadunidenses de primeira hora procuraram estabelecer condições científicas, sociais e legislativas com o firme propósito de controlar efetivamente a capacidade reprodutiva dos indivíduos classificados e catalogados como inaptos eugenicamente.

Influenciados pela crescente importância da redescoberta dos princípios genéticos de Mendel, em princípios do século xx, para a compreensão dos mecanismos da hereditariedade, principalmente com a admissão da existência de caracteres dominantes e recessivos quando dos cruzamentos entre indivíduos, os eugenistas estadunidenses estavam convencidos de que bastaria, ao pesquisador de campo eugenista, determinar quais caracteres nocivos poderiam ser dominantes e estabelecer procedimentos visando impedir a sua proliferação (cf. Selden, 1999, p. 2-4).

As descobertas mendelianas representaram para os eugenistas uma orientação científica rigorosa, pois, de acordo com o rigor da teoria mendeliana, existiriam fatores internos que poderiam ser distribuídos nas gerações através da "repartição estatística dos fatores hereditários que produzem uma primeira geração híbrida fenotipicamente uniforme, que se dispersa em continuação, nas gerações seguintes, segundo as regras da probabilidade" (Buican, 1987, p. 19). Por haver fatores internos que seriam transmitidos sem sofrerem alguma ingerência do meio, a não ser como fator 
selecionador, os eugenistas, de modo particular os estadunidenses, perceberam na teoria mendeliana um pressuposto científico suficientemente sólido para a defesa da necessidade de programas que supostamente favoreceriam a seleção e a continuidade de características consideradas superiores e, por conseguinte, proporcionariam o surgimento de condições de aperfeiçoamento das disposições humanas e, consequentemente, das condições sociais entendidas como decorrentes de disposições humanas consideradas inatas (cf. Kevles, 2001, p. 7०).

Todavia, o alcance e a importância da teoria mendeliana para os propósitos eugênicos não representava consenso no meio eugenista mais amplo. Por exemplo, os eugenistas britânicos, ligados a uma leitura darwiniana e biométrica com relação à distribuição e herança de características humanas consideradas internas e não sujeitas às vicissitudes das condições externas - isto é, socioambientais -, apontavam as dificuldades da aplicação dos mesmos procedimentos usados com plantas e animais no tratamento das potencialidades humanas. Por outro lado, os eugenistas mendelianos argumentavam que não somente seria possível, como também seria necessário aplicar os mesmos critérios aos seres humanos. Os primeiros se reuniram em torno de Galton, compondo o grupo inglês, defensores da necessidade de se construir condições selecionadoras para o favorecimento da proliferação das melhores características; enquanto os outros se reuniram em torno de Charles Benedict Davenport (1866-1944), que juntamente com Harry Hamilton Laughlin (1880-1943) formaram o grupo estadunidense, defensores da necessidade de se construir mecanismos de controle reprodutivo com o propósito de exterminação das características indesejadas (cf. Farral, 1975).

Proibições de casamentos, anulações e exigência de exames pré-nupciais, com nítida preocupação eugênica, foram estabelecidas nos Estados Unidos, França e Alemanha (cf. Barret \& Kurzman, 2004). Mas tudo isso não era ainda suficiente. O simples controle das relações matrimoniais não representava, para os eugenistas estadunidenses, avanços substantivos em sua meta de erradicação dos elementos responsáveis pela hereditariedade dos traços degenerescentes (cf. Davenport, $192^{2}$ [1911], p. 1).

Nos Estados Unidos, as condições sociais do início do século xx, marcadas por um crescimento significativo do fluxo de imigrantes vindos de todas as partes do mundo, motivaram, na elite americana, o surgimento da preocupação com relação à qualidade dos indivíduos que o país recebia. Por mais que os estadunidenses se considerassem como um país de imigrantes, esse sentimento estava reservado aos indivíduos vindos do norte 
da Europa, de ascendência nórdica, considerados representantes de uma linhagem superior, eugenicamente distinta de outros povos (cf. Waters \& Eschbach, 1995).

Face ao sentimento de que a pureza da descendência americana estava sendo ameaçada pela proliferação tanto de imigrantes de origem inferior quanto pela miscigenação de indivíduos degenerados, os eugenistas estadunidenses se mobilizaram para reunir evidências que legitimassem, em uma possível defesa científica da discriminação, medidas restritivas e corretivas. Tal empreitada coube à pessoa de Charles B. Davenport, que assumiu a missão de construir as condições institucionais para a implementação de programas de melhoria das disposições hereditárias da população estadunidense (cf. Davenport, 1909, p. 20).

Davenport estava seguro de que somente o conhecimento genético poderia fornecer as informações necessárias para o melhoramento da espécie humana. Pensava, consequentemente, que uma política de melhoramento genético só poderia ser conduzida mediante informação científica consistente, baseada, sobretudo, em dados experimentais a partir do controle reprodutivo de espécies consideradas inferiores (cf. Davenport, 1921, p. 391).

A carreira de Davenport como líder do movimento eugênico nos Estados Unidos começou a se desenhar quando ele dirigia o laboratório de biologia do Brooklyn Institute of Arts and Science, em Cold Spring Harbor. No local, para aumentar sua renda, Davenport começou a oferecer um curso de verão muito concorrido, que atraía um número cada vez maior de jovens. Assim foram lançadas as sementes do que aos poucos se transformaria na "meca espiritual" de eugenistas ao redor do mundo (cf. Kevles, 2001, p. 51).

As ideias de Galton causaram em Davenport verdadeiro fascínio. Desde o primeiro momento Davenport percebeu na proposta de uma ciência eugênica a possibilidade de se encontrar, a partir do avanço da pesquisa experimental, instrumentos para intervir no curso da reprodução humana (cf. Carlson, 2001, p. 194; Paul, 1995, p. 8). $\mathrm{Na}$ virada do século, com a redescoberta das leis de Mendel, Davenport vislumbrou a possibilidade de transformar as ideias galtonianas de melhoramento das características hereditárias humanas por meio de experimentos laboratoriais (cf. Kevles, 2001, p. 54-6; Paul, 1995, p. 39-49).

Ao arquitetar o seu projeto de melhoramento de traços humanos hereditários, Davenport considerava que isso só poderia tornar-se realidade se, além de instalações apropriadas, houvesse uma congregação de esforços institucionais, acadêmicos e financeiros no sentido de dar sustentabilidade para o programa eugênico. Para tanto, mesmo sendo um indivíduo ensimesmado, até avesso a contatos sociais, Davenport transformou-se no maior propagandista da eugenia nos Estados Unidos e reuniu, sob o ideário eugênico de melhoramento das disposições hereditárias da população, milio- 
nários filantropos, agremiações representativas de setores econômicos, órgãos governamentais, instituições científicas e departamentos universitários (cf. Kevles, 2001, p. 54-56; Paul, 1995, p. 8-11).

O primeiro passo de Davenport foi articular o apoio de uma grande e famosa instituição. Assim, em 1902, vislumbrou na recém-criada Carnegie Institution o ponto de apoio institucional e financeiro para os seus propósitos. Davenport enviou àquela instituição uma série de relatórios e cartas procurando convencer os curadores sobre a urgência de se criar um laboratório de pesquisa para realizar experimentos de melhoramento de traços humanos considerados indesejáveis. Depois de várias investidas, os membros da Carnegie Institution se convenceram da relevância do empreendimento e da sua importância para o desenvolvimento da ciência e para o futuro da nação americana. Com isso, em 19 de janeiro de 1904, deu-se início formal ao programa eugênico de melhoramento das características da população estadunidense, mediante a fundação da Station for Experimental Evolution of the Carnegie Institution (SEE) em Cold Spring Harbor (cf. Allen, 1986, p. 209-230).

No início, os experimentos realizados com plantas e animais sugeriam aos adeptos da eugenia a possibilidade de se controlar experimentalmente também a reprodução humana, no sentido de se encontrar fatores mendelianos responsáveis por características degenerativas presentes nos seres humanos. E assim, segundo Davenport, a questão prática para a estação experimental seria:

O que pode ser feito para a redução da frequência da debilidade mental e de traços corporais que são encargos demasiados para nossa população? Essa questão tem sido por muitas vezes solicitada. Ela tem sido respondida de diversas formas, e, na verdade, há vários métodos para parar a reprodução de traços indesejáveis (Davenport, 1972 [1911], p. 256).

Com o propósito de ampliar ainda mais o campo institucional e de pesquisa, Davenport percebeu que a American Breeders Association (ABA) - uma associação fundada em 1903 com o propósito de unir esforços de criadores de animais e especialistas em sementes para produzir pesquisas que fizessem avançar a produtividade e a qualidade de seus produtos (cf. Kimmelman, 1983, p. 166) - poderia ser um novo parceiro institucional no estabelecimento de bases experimentais que produzissem conhecimentos passíveis de serem aplicados também no melhoramento das características humanas (cf. Allen, 1986, p. 232).

Com essas primeiras ações institucionais, as condições materiais e alguns aspectos experimentais foram estabelecidos, assim faltava apenas a Davenport criar um dispositivo de trabalho de campo que pudesse transformar a sociedade em um grande 
laboratório de pesquisa, rastreando e catalogando os indivíduos para coletar informações que pudessem sustentar medidas de controle reprodutivo dos considerados eugenicamente inaptos. Para tanto, Davenport precisava urgentemente encontrar e determinar quais seriam os indivíduos portadores do que os eugenistas classificavam de germeplasma defeituoso, e assim buscar medidas corretivas que levassem à sua eliminação (cf. Davenport, 1909). Os seus primeiros passos consistiram em, juntamente com Alexandre Graham Bell (1847-1922), um dos principais membros da ABA e eugenista convicto, distribuir um questionário de registro familiar em escolas e universidades, procurando registrar informações sobre históricos familiares no que dizia respeito à existência de debilidade mental e deficiência visual ou auditiva em algum aparentado (cf. Black, 2003, p. 101).

Com este pequeno ato, Davenport percebeu duas consequências importantes para os seus propósitos eugênicos: primeiro, a necessidade de reunir informações sobre os eugenicamente indesejáveis, o que representava um método de trabalho a ser seguido; e, segundo, a necessidade da criação de um órgão que se responsabilizasse pelo trabalho de campo, o que incluía a catalogação dos dados e posterior análise. Esse órgão poderia estar associado ao Comitê Eugênico da ABA, mas teria responsabilidades e funcionalidades independentes, traduzindo as suas pesquisas de campo e as pesquisas laboratoriais de base feitas pela SEE em propostas de políticas governamentais para a sociedade americana. Estava vislumbrado o terceiro instrumento institucional para a implementação de medidas eugênicas, o Eugenics Record Office (ERO) (cf. Allen, 1986, p. 226).

A criação do ERO envolveu novamente uma complexa conjugação de esforços por parte de Davenport, o que incluía fatores de competência técnica e política para o estabelecimento de um campo de produção de conhecimento científico no que diz respeito ao controle hereditário dos traços comportamentais degenerantes. Com o ERO, Davenport procurou conjugar práticas laboratoriais e estratégia política com o propósito de estabelecer um campo de articulação no qual o conhecimento científico de base e as ações sociopolíticas contribuiriam para consolidar e legitimar a eugenia como um programa de pesquisa científico. Tal como assinala Pierre Bourdieu, os campos científicos podem ser compreendidos como o lugar do estabelecimento de duas formas de poder, correspondentes a duas espécies de capital:

De um lado, um poder que se pode chamar temporal (ou político), poder institucional e institucionalizado que está ligado à ocupação de posições importantes nas instituições científicas, direção de laboratórios ou departamentos, pertencimentos a comissões, comitês de avaliação, etc., e ao poder sobre os meios de produção (contratos, créditos, postos, etc.) e de reprodução (poder de nomear e 
fazer as carreiras) que ela assegura. De outro, um poder específico, 'prestígio' pessoal que é mais ou menos independente do precedente, segundo os campos e as instituições, e que repousa quase exclusivamente sobre o reconhecimento, pouco ou mal objetivado e institucionalizado, do conjunto de pares ou da fração mais consagrada dentre eles, por exemplo, com os "colégios invisíveis" de eruditos unidos por relação de estima mútua (Bourdieu, 2004, p. 35).

Na conjugação dessas duas formas de capital, Davenport primeiramente percebeu que era preciso encontrar alguém que financiasse o projeto e que, ao mesmo tempo, fosse representativo da elite financeira e racial que ele pretendia orientar, a partir dos princípios de uma ciência eugênica, em direção ao estabelecimento de um ambiente social livre dos indivíduos eugenicamente inaptos ou degenerados.

As intenções de Davenport encontraram eco no magnata das ferrovias Edward Henry Harriman (1848-1909), um entusiasta das ciências e financiador de vários projetos científicos. Harriman havia falecido e deixado sua fortuna aos cuidados de sua esposa, Mary Harriman (1851-1932), com quem Davenport logo procurou estreitar relações no sentido de aproximá-la do ideário eugênico. Davenport não precisou de muitos esforços para convencê-la da importância da participação do nome Harriman na edificação de uma nova nação construída sobre as bases eugênicas. Em fevereiro de 1910, a senhora Harriman concordou definitivamente em financiar o projeto (cf. Paul, 1995, p. 8-10; Allen, 1986, p. 234-5). Iniciava-se, com essas medidas, a caçada aos eugenicamente indesejáveis, faltando apenas a Davenport encontrar um executor de tal ideário.

Davenport, desde o início, procurou dar ao ERO a conotação de que se tratava de um empreendimento conjunto da $\mathrm{ABA}$ - e seus estritos laços com o governo americano - com o status econômico representado pelo nome Harriman. Isso fazia do ERO, muito embora parecesse um anexo da SEE, uma instituição independente e fruto de um projeto comum da ABA e da senhora Harriman. Com isso Davenport conseguiu manter três instituições trabalhando sob seu comando - o Comitê Eugenista/ABA, a SEE e o ERO - recebendo apoio financeiro e institucional, bem como respeitabilidade pública. Dessa forma, Davenport atraiu para os seus projetos um número crescente de financiadores esperançosos de estarem contribuindo como benfeitores da humanidade (cf. Paul, 1995, p. 8-10).

No final da primeira década do século xx, o projeto de Davenport ganhou proporções que exigiam esforços de outros membros tão combativos quanto ele próprio. Com efeito, ao definir os objetivos do ERO enquanto um órgão de pesquisa de campo e de políticas, Davenport necessitava de alguém para dirigi-lo que, além de formação científica, ansiasse desesperadamente por reconhecimento e acreditasse sem reser- 
vas na urgência de impedir a proliferação dos eugenicamente indesejáveis. Davenport encontrou tudo isso na pessoa de Henry Laughlin (1880-1943), um antigo aluno de seus cursos de verão, com o qual se encontrara novamente em 1909 em um congresso da ABA, mantendo desde então as mesmas aspirações eugênicas (cf. Carlson, 2001, p. $235-4,3)$.

Laughlin foi contratado para dirigir o escritório por um período inicial de dez anos, com um salário de 2.4,00 dólares anuais mais despesas, o que aceitou prontamente. No final de 1910, Laughlin e família já estavam instalados nas dependências do ERO. Em outubro do mesmo ano, o Eugenics Record Office foi inaugurado com a missão de "realizar pesquisa sobre hereditariedade humana, especialmente a herança de traços sociais; e educar os leigos sobre a importância da pesquisa eugênica e as implicações da eugenia no estabelecimento de políticas públicas" (Allen, 1986, p. 238).

Laughlin dedicou-se de corpo e alma ao ERO e logo colocou em funcionamento a máquina eugênica de identificação, catalogação e restrição dos considerados inaptos à reprodução. $\mathrm{O}$ trabalho consistia em identificar o número de americanos deformados e indesejáveis, estimado no mínimo em dez por cento da população (cf. Carlson, 2001, p. 242). Aliás, essa cifra virou referência no debate. Falava-se naturalmente da existência de dez por cento da população que deveria ser submetida a "tratamento apropriado", no sentido de acabar com a cadeia reprodutiva. Várias propostas de tratamento foram consideradas, mas, por uma questão estratégica, resolveu-se que os principais métodos deveriam ser a segregação e a esterilização (cf. Carlson, 2001, p. 241-2).

Utilizando o mesmo tipo de metodologia que se usava para a identificação de animais, os pesquisadores do ERO tinham como missão relacionar as linhagens das famílias americanas, denominadas de pedigrees. ${ }^{\mathbf{1}}$ Depois de um breve período de treinamento, os pesquisadores empreenderam as pesquisas de campo com a intenção de levantamento de dados sobre os considerados eugenicamente inferiores, suas famílias e sua concentração geográfica. Os primeiros alvos foram as prisões e as instituições de tratamento mental, depois estendeu-se para qualquer canto do país onde houvesse alguém considerado portador de alguma degenerescência, mesmo que isso significasse apenas um comportamento diferente dos demais (cf. American Breeders Association, 1909). Em carta enviada às instituições, Laughlin expõe os objetivos eugênicos:

o trabalho deste escritório consiste amplamente na coleta e estudo de registros das melhores famílias americanas. Neste trabalho estamos interessados no registro familiar como um pedigree que demonstre a distribuição e herança de cer-

1 Para uma relação dos pedigrees levantados pelas equipes de campo do ERO ver: <http://www.eugenicsarchive.org/ html/eugenics/static/themes/5.html>. 
O Gontrole De GaraGterístigas genéticas humanas...

tas qualidades físicas, mentais e sociais. Um de seus parentes preparou um desses estudos para o seu próprio ramo familiar, e aproveitamos esta ocasião para perguntar se vocês estão interessados em estender esse registro para sua própria seção da árvore-familiar. O registro agora em sua posse está cuidadosamente indexado e permanentemente preservado, e será usado somente para uso da família descrita e para estudo científico; não será publicado sem a instrução dos familiares. Se você se interessar em dar continuidade a este estudo, estendendoo à sua família particular, nós gostaríamos de enviar duas cópias em branco de cédulas chamadas de Registro de Traços Familiares. Eles são sempre enviados duplamente para que a pessoa que preencheu possa reter uma cópia para uso próprio e possa arquivar o segundo ou a duplicata nos arquivos permanentes deste escritório (Laughlin, 1922).

Acolhidos com entusiasmo por administradores de asilos, prisões, hospitais psiquiátricos, casas de caridades e autoridades de pequenas localidades rurais, os pesquisadores de campo do ERO se espalharam por todos os cantos dos Estados Unidos. O simples fato de não falar corretamente o inglês já era um indício suficiente de debilidade mental e passível de registro para controle reprodutivo. Os métodos de abordagem dos pesquisadores eram desde questionários formais e catalogação dos registros das instituições até o estabelecimento de contatos simpáticos, procurando ganhar a confiança das pessoas para levantar dados sobre elas e seus parentes (cf. Allen, 1986).

Os candidatos à esterilização ou à segregação em campos ou fazendas especiais consistiam em todo um conjunto de indivíduos marcados pela diferença e por condições sociais desfavoráveis. Assim, além de criminosos, os pesquisadores estavam atrás de albinos, surdos, cegos, débeis mentais, pessoas acometidas por doenças consideradas incuráveis, miseráveis e prioritariamente os epilépticos (cf. Reilly, 1987). Para o ERO, a pobreza e a epilepsia estavam naturalmente associadas e eram sinônimos de debilidade mental. Os sentidos treinados dos pesquisadores de campo do ERO catalogaram além dos severamente retardados, também qualquer um que se apresentasse como tímido, introvertido, calado, gago, mudo e os que falavam inglês incorretamente. $\mathrm{O}$ critério era tão amplo que foram registradas como epilépticas pessoas acometidas por enxaquecas e mesmo aquelas com desmaios por outras causas. Como instrução para o trabalho de campo, o boletim do ERO sobre o estudo da hereditariedade humana declarava:

por muitos anos as melhores organizações hospitalares e instituições de deficientes têm mantido registros familiares dos pacientes. Da informação obtida por aplicação de formulários, os médicos têm computado, tabulado e deduzido. 
Mas, tem-se notado há algum tempo que tais registros estão longe de ser satisfatórios e que a melhor maneira de obter a herança da epilepsia, debilidade mental, criminalidade e de várias formas de insanidade é por meio de trabalhadores de campo, indo até as casas e entrevistando as pessoas que podem e darão a informação desejada (Eugenics Record Office, 1911).

Nesse contexto, em maio de 1911, em Palmer, Massachusetts, o comitê eugenista da ABA decidiu criar um novo comitê especial, com um objetivo bem definido: eliminar o germeplasma defeituoso. No dia 15 de julho de 1911, Laughlin e os principais membros do comitê da ABA reuniram-se no City Club, em Manhattan, para debater como resolver o problema da proliferação dos degenerados. Nessa reunião foram traçadas algumas diretrizes importantes para o futuro da população estadunidense. Primeiramente, concordou-se que o futuro da população dependia não somente de se impedir a reprodução do indivíduo portador de degenerescência, mas sim a identificação do germeplasma defeituoso presente em toda a família, mesmo que não tenha se manifestado, estabelecendo assim uma nova categoria de indesejáveis: os assintomáticos. Além disso, os "degenerados", "incapazes sociais" e alvos das medidas de limpeza racial foram agrupados em dez categorias principais: (1) deficientes mentais, (2) indigentes, (3) alcoólatras, (4) criminosos, (5) epilépticos, (6) insanos, (7) constitucionalmente frágeis, (8) predispostos a doenças específicas, (9) fisicamente deformados e (10) deficientes quanto aos órgãos dos sentidos. Em uma conta preliminar feita pelos próprios eugenistas, no total isso representaria onze milhões de pessoas (cf. Black, 2003, p. 121).

Laughlin estimava que em 15 ou 30 anos, após medidas eficazes que envolviam matrimônio restritivo, controle compulsório da natalidade, segregação obrigatória e perpétua e até esterilização dos inaptos, a nação americana estaria livre das características degenerescentes e pronta para edificar uma nova e purificada linhagem hereditária. Para multiplicar a linhagem genética desejável, Laughlin sugeria até a poligamia e a procriação sistemática, uma ideia que seria posta em prática na Alemanha nazista, em 1935, por Heinrich Himmler, com a inauguração do Lebensborn, instituição responsável pela reprodução sistemática e controlada de indivíduos representativos da pura raça ariana.

Após livrar os Estados Unidos dos eugenicamente indesejáveis, os eugenistas, liderados por Laughlin e Davenport, vislumbravam estender as medidas eugênicas para além das fronteiras estadunidenses, caçando os eugenicamente inaptos onde eles se encontrassem, de modo a livrar, primeiramente, os Estados Unidos e depois o mundo do germeplasma defeituoso (cf. Black, 2003, p. 126). 
Os planos de internacionalização dos programas eugênicos de Davenport e Laughlin começaram a tornar-se realidade em 1912, com a realização do Primeiro Congresso Internacional de Eugenia em Londres.

Ainda sob a força da influência do mais importante teórico da eugenia, Francis Galton, que tinha morrido um ano antes, esse congresso, que teve como presidente de honra o Major Leonard Darwin (1850-1943), filho de Charles Darwin, representou para os eugenistas estadunidenses o ponto de partida para a criação de um organismo internacional que coordenasse as ações eugênicas. Com representantes vindos de vários países, o encontro foi dominado pelos delegados provenientes dos Estados Unidos, Alemanha, Bélgica, Itália e França, além obviamente dos anfitriões ingleses.

Para organizar o movimento internacionalmente foi deliberada a criação de um Comitê Internacional de Eugenia, que viria a se reunir um ano depois, em 4 de agosto de 1913, em Paris. Dentre as questões a serem resolvidas, havia a da continuidade das ações de cooperação internacional e também a da realização de um segundo congresso, a ser decidida em nova reunião marcada para 15 de agosto de 1914, na Bélgica.

O segundo congresso eugenista deveria ter sido realizado em 1915, mas a Europa e o mundo viram-se envolvidos na Primeira Grande Guerra, de modo que os planos dos eugenistas tiveram que ser adiados à espera de um momento mais oportuno (cf. Carlson, 2001, p. 267-9; Pearl, 1912, p. 396). Com efeito, o segundo congresso só viria a acontecer em setembro de 1921, na cidade de Nova York. A organização do congresso coube à linha de frente do movimento eugenista americano: a senhora Harriman, Laughlin e o curador do Museu de História Natural da cidade de Nova York, à época considerado o maior especialista mundial em raça, Madison Grant $\left(1865^{-193}\right.$ ). A relação entre o Museu de História Natural e o congresso eugenista era tão íntima que dava a entender que o evento fazia parte das ações da programação do Museu, o que conferia ao encontro o status de um importante e respeitado evento científico (cf. Cocks, 1994).

O modelo americano de eugenia dominou completamente o encontro, motivando críticas de delegados de outros países. Por exemplo, dos cinquenta e três trabalhos apresentados, somente doze não foram produzidos ou não refletiam temas de interesses dos americanos (cf. Mehler, 1988, p. 36-41). Diferentemente do que aconteceu no primeiro, no segundo congresso o movimento eugênico já obedecia às orientações do grupo ligado a Davenport e Laughlin e o problema da reprodução dos indesejáveis se tornava o ponto central dos trabalhos apresentados (cf. Osborn, 1968, p. 312).

Uma das deliberações importantes do segundo congresso para o avanço do movimento eugenista, em termos mundiais, foi a mudança e redefinição das competências do Comitê Internacional, tornando-se a Comissão Internacional Permanente de 
Eugenia, sob o controle diretivo de Davenport e com poderes sobre as organizações eugênicas presentes em uma série de países membros, a saber: Argentina, Austrália, Bélgica, Brasil, Colômbia, Cuba, Dinamarca, Estados Unidos, França, Grã-Bretanha, Itália, México, Noruega, Nova Zelândia, Países Baixos, Suécia (cf. Black, 20o3, p. 39o).

Alguns anos mais tarde, em 1925, visando maior padronização dos métodos de ação, a Comissão Internacional de Eugenia sofreu uma nova reformulação mudando o seu nome para International Federation of Eugenics Organization (IFEO). Através de memorando enviado às sociedades membros, Davenport reiterava o objetivo da organização:

Tentar assegurar alguma medida de uniformidade nos métodos de pesquisa, e ainda suficiente uniformidade na forma de apresentação dos resultados, de modo a fazer com que o trabalho internacional tenha utilidade no mundo inteiro. Tentar promover medidas que se inclinem pelo progresso eugenista, internacional ou nacional, sobre linhas comparativas (Davenport apud Black, 2003, p. 393).

No terceiro congresso internacional de eugenia, realizado em 1932, novamente no Museu de História Natural, os adeptos do movimento eugênico, a despeito de inúmeras críticas, ainda mantinham a firme convicção de que a eugenia se constituía em uma prática científica legítima. O conhecimento sobre o domínio da reprodução humana, orientado através de rígidos preceitos eugenistas, estava pronto para ser conduzido não apenas como práticas de pesquisas laboratoriais, mas, principalmente, como políticas públicas de saúde para a higiene racial (cf. Laughlin, 1922, p. 446). A essa altura, Laughlin já tinha elaborado um modelo de legislação para orientar as medidas públicas, que mais tarde foram levadas até as últimas consequências na Alemanha nazista de Adolf Hitler (cf. Weiss, 1987).

Os congressos internacionais de eugenia fizeram parte de um esforço de institucionalização internacional do movimento eugênico. A busca por uma sólida institucionalização foi uma característica que marcou a eugenia desde o seu início com o laboratório de antropometria de Francis Galton, com a transformação de sociedades em instituições de orientação eugênica e com a criação de laboratórios e instituições voltados exclusivamente para o desenvolvimento de programas eugênicos. Tais foram os casos do Biometric Laboratory (fundado em 1902) e do Galton Laboratory (fundado em 1904.) - mais tarde reunidos no Galton Eugenics Laboratory of the University of London (em 1907) - e também da Eugenics Educations Society, fundada em 1908 por membros participantes da Moral Education League, uma associação preocupada com as consequências sociais dos vícios, principalmente do alcoolismo e do uso apropriado da caridade (cf. Magnello, 1999, p. 144-5). Muito embora os trabalhos conduzidos pelas várias 
instituições, de uma forma ou de outra ligadas ao movimento eugênico, não tenham sido orientados exclusivamente pelos princípios da eugenia, ainda assim, questões eugênicas eram correntes e suscitavam preocupações constantes (cf. Magnello, 1999).

A facilidade com que as ideias eugênicas se espalharam pelo mundo não foi obra exclusiva do grupo estadunidense e das campanhas propagandistas de Laughlin. A preocupação com a qualidade racial da população há muito tempo era acalentada nos quatro cantos da terra. As íntimas relações com as teorias raciais do século xIx e com as teorias higienistas e sanitárias do início do século xx compõem um quadro mais amplo para o entendimento da extensão do movimento eugênico. O que podemos indicar, contudo, é que o que se encontrava diluído entre a literatura raciológica, antropométrica, craniométrica e frenológica, orientando trabalhos em áreas dispersas como antropologia criminal, sociologia e bioestatística, foi reunido em torno da eugenia enquanto um programa científico e social de melhoramento das características hereditárias humanas.

\section{V}

Desde o seu início, em 1883, quando Francis Galton cunhou o termo, podemos considerar que o movimento eugênico procurou se estabelecer como um campo de articulação de conhecimentos científicos e práticas socioculturais articuladas politicamente por ações individuais, institucionais e governamentais, por intermédio de ações laboratoriais, políticas e legais com a finalidade de regulamentar as relações matrimoniais, mediante exames pré-nupciais e esterilização dos considerados inaptos. Sua marca institucional, com a formação de agremiações, sociedades e associações eugênicas na Europa, Estados Unidos, América Latina, Índia e Ásia, leva-nos a considerar que boa parte dos programas eugênicos foi conduzida através de ações relacionadas a medidas profiláticas, sanitárias, higiênicas, de saúde pública, controle de enfermidades, controle populacional e de natalidade, conduzidas por movimentos de saúde pública, ligados direta ou indiretamente às instituições eugênicas. Como nos lembra André Pichot acerca do estabelecimento de legislações que traziam em seu escopo a inspiração eugenista:

De fato, essas legislações não aparecem por geração espontânea. Os legisladores não decidiram, de um dia para o outro, por pura fantasia, promulgar leis eugenistas. Há um grande silêncio a este respeito, mas a verdade é que o impulso primeiro foi dado por associações dirigidas por médicos e biólogos. Essas asso- 
ciações, através da propaganda e de um lobbying intensivo, fizeram pressão sobre os legisladores (a mais ativa terá sido a American Eugenics Society, que publicou um Catecismo eugenista e que organizou concursos de palestras para a pregação de sua doutrina). O suporte e a caução científica que lhes concederam os grandes nomes da biologia, e especialmente da genética, foram sem dúvida determinantes. No fim do século xIx e princípio do século xx, após os trabalhos de Pasteur sobre as doenças contagiosas, foram postas em prática políticas de higiene pública. As leis eugenistas foram introduzidas nesse movimento legislativo. Enquanto as medidas de higiene pasteurianas (declaração das doenças contagiosas, vacinação, quarentena etc.) visavam impedir a propagação das epidemias, as leis eugênicas deveriam travar a propagação das doenças e das taras hereditárias (preocupação irracional porque cedo houve a percepção de que os argumentos nesse sentido eram cientificamente bastante fracos e que a saúde pública não tinha muito a temer nesse campo). Essas leis se beneficiaram seguidamente, sem dúvida, dos movimentos favoráveis ao controle dos nascimentos; a um controle quantitativo (o número de filhos) juntar-se-ia um controle qualitativo (eugenia). Acabariam, por fim, por parasitar mais ou menos as políticas de apoio social (Pichot, 1996, p. $48-50)$.

Nesse sentido, precisamos estender a compreensão acerca da natureza do movimento eugênico, e entendê-lo a partir da colaboração conceitual de Pierre Bourdieu como um campo de articulação de conhecimentos científicos e práticas sociais (cf. Ortiz, 2005), onde, de acordo com o raciocínio eugênico, os propósitos do Estado coincidiriam com os propósitos de uma racionalidade técnico-científica voltada para o controle reprodutivo e para o melhoramento das características hereditárias dos seres humanos. Caberia, portanto, na concepção dos eugenistas, ao Estado determinar os rumos e a qualidade de sua população, pois haveria, no final, uma estreita sintonia entre os interesses individuais e os coletivos, representados no Estado. O Estado deveria favorecer o desenvolvimento de uma população sadia, superior intelectualmente, e impedir a proliferação e reprodução dos degenerados. Com efeito, os fundamentos que sustentariam tais práticas seriam fornecidos por dados provenientes da ciência eugênica (cf. Barret \& Kurzman, 2004, p. 502; Carlson, 2001, p. 273-6).

A relação entre programas eugênicos e políticas públicas, principalmente com relação à saúde da população e ao controle reprodutivo, foi mais estreita ou mais larga dependendo da orientação teórica seguida pelos adeptos do movimento eugênico espalhados por diferentes países. Ademais, mesmo considerando a fluidez do movimento eugênico, as ações institucionais e as medidas legislativas adotadas internacionalmente 
seguiram, em linhas gerais, duas fortes orientações. Uma orientação foi dada pelo que podemos considerar o modelo estadunidense de eugenia, que defendia a concepção de que tanto características físicas quanto psicológicas seriam transmitidas dos indivíduos à prole, obedecendo aos critérios da teoria mendeliana. Em outra direção, podemos considerar o modelo de orientação higienista, que defendia que as condições ambientais provocariam reações orgânicas que seriam incorporadas ao material genético dos indivíduos e transmitidas para a prole, aumentando a incidência das características degenerativas entre a população - em estreita sintonia com uma perspectiva neolamarckiana (cf. Kevles, 2001, p. 41-49).

Ademais, procuramos demostrar com este artigo que a forte influência da eugenia nas primeiras décadas do século $\mathrm{xx}$ deveu-se, de modo particular, a um conjunto de ações institucionais com o firme propósito de oferecer legitimidade sociopolítica e científica às pretensões eugênicas de controle da qualidade hereditária da população, através do estabelecimento de um campo científico onde se articularam instituições de pesquisa de base, como a SEE (Station for Experimental Evolution), órgãos de pesquisa de campo e análise, como o ERO (Eugenics Record Office), e outras organizações de natureza eugenista, nacionais e internacionais. Esse conjunto de práticas institucionalizadas acabou por influenciar políticas sociais de saúde e sanitárias, bem como medidas legislativas e jurídicas e, até, reformas educacionais.

Agradecimentos. O presente texto faz parte das pesquisas de doutorado em ciências sociais e pós-doutorado em teoria antropológica (em andamento), com auxílio de bolsa FAPESP de pós-doutorado (2009/15627-3), ambas realizadas no Departamento de Antropologia da Universidade Estadual de Campinas, aos quais eu agradeço pelas condições, apoio e recursos.

Valdeir DEL ConT

Universidade Paulista, Campinas, Brasil. valdeirdelcont@hotmail.com

The control of human genetic characteristics and the institutionalization of eugenic social-cultural practices 


\begin{abstract}
One of the characteristics of the eugenic movement was the formation of an institutionalized structure. This was initiated with Francis Galton, but it is in the United States that eugenics acquires institutional formatting that would serve as model for various eugenics initiatives in other parts of the world. In this text we intend to analyze some of the conditions that contributed for eugenics to be presented as a scientific proposal of social control of traces or characteristics considered genetically determined.
\end{abstract}

KEYwORDs • Eugenics. Eugenics institutions. Social control of genetic characteristics. Race. Racial improvement.

\title{
REFERÊNGIAS BIBLIOGRÁFIGAS
}

Alten, G. E. The Eugenics Record Office at Cold Spring Harbor, 1910-1940: an essay in institutional history. Osiris, series 2, 2, p. 225-64, 1986.

American Breeders Association. Eugenics, a subject for investigation rather than instruction. American Breeders Association Eugenics Section, 1909. Disponível em: $<$ http://www.dnalc.org/view/104,00Eugenics-a-subject-for-investigation-rather-than-instruction-American-Breeders-AssociationEugenics-Section.html>. Acesso em: 27 set. 2013.

Barret, D. \& Kurzman, C. Globalization social movement theory: the case of eugenics. Theory and Society, 33, p. $4.87-527,2004$.

BLAGK, E. Guerra contra os fracos: a eugenia e a campanha dos Estados Unidos para criar uma raça dominante. Tradução T. Magalhães. São Paulo: A Girafa, 2003.

Blanckaert, G. Lógicas da antropotecnia: mensuração do homem e bio-sociologia (1860-1920). Revista Brasileira de História , 21, 41, p. 145-56, 2001.

Bourdieu, P. Os usos sociais da ciência: para uma sociologia clínica do campo científico. São Paulo: Editora Unesp, 2004.

Buican, D. A genética e a evolução. Tradução E. C. Lima. Lisboa: Publicações Europa-América, 1987.

Carlson, E. A. The unfit: a history of a bad idea. Cold Spring Harbor, New York: Cold Spring Harbor Laboratory Press, 2001.

Castañeda, L. A. Eugenia e casamento. História, Ciência, Saúde-Manguinhos, 10, 3, p. 901-3o, 2003.

Cocks, G. The international eugenics community. Reviews in American History, 22, 4, p. 674-8, 1994.

Cont, V. Del. Francis Galton: eugenia e hereditariedade. Scientiae Studia, 6, 2, p. 201-18, 2008.

Cowan, R. S. Francis Galton's statistical ideas: the influence of eugenics. Isis, 63, 4, p. 5०9-28, 1972.

Darmon, P. Médicos e assassinos na belle époque: a medicalização do crime. Tradução R. G. de Agostinho. Rio de Janeiro: Paz e Terra, 1991.

Davenport, C. B. Influence of heredity on human society. Annals of the American Academy of Political and Social Science, 34, 1, p. 16-21, 1909.

. Research in eugenics. Science, new series, 54, 14,00, p. 391-7, 1921.

. Heredity in relation to eugenics. New York: Arno Press/The New York Times, 1972 [1911].

Eugenics Record Office. The study of human heredity. Bulletin 2, 1911. Disponível em: <http://www.dnalc. org/view/11695-The-Study-of-Human-Heredity-by Davenport-Laughlin-Weeks-Johnstone-andGoddard-Eugenics-Record-Office- Bulletin-No-2-9-.html>. Acesso em: 21 set. 2013.

FARRAL, L. A. Controversy and conflict in science: a case study. The English biometric school and Mendel's laws. Social Studies of Science, 5, 3, p. 269-301, 1975. 


\section{O GONTROLE DE GARAGTERÍSTIGAS GenÉtigas huMANAS...}

GaLton, F. F. Blood-relantionship. Nature, 6, p. 173-6, 1872 .

On recent designs for anthropometric instruments. The Journal of the Anthropological Institute of Great Britain and Ireland, 16, p. 2-9, 1887 .

Hereditary genius. London: Macmillan and Co., 1892.

Eugenics: its definition, scope, and aims. The American Journal of Sociology, 10, 1, p. 1-25, 1904.

Disponível em: <http://galton.org/essays/1900-1911/galton-1904-am-journ-soc-eugenics-scopeaims.htm>. Acesso em: 21 set. 2013.

. Memories of my life. London: Methuen, 1908. Disponível em: <http://galton.org/books/memories/ index.html $>$. Acesso em: 21 set. 2013.

Goddard, H. The Kallikak family: a study in the heredity offeeble-mindedness. New York: MacMillan, 1912. Disponível em: 〈http://psychclassics.yorku.ca/Goddard/>. Acesso em: 21 set. 2013.

Kenna, J. C. Sir Francis Galton's contributions to anthropology. The Journal of Anthropological Institute of Great Britain and Ireland, 94, 2, p. 80-93, 1964.

Kevles, D. In the name of eugenics: genetics and the uses of human heredity. New York: Alfred A. Knopf, 2001.

Kimmelman, B. A. The American's Breeders Association: genetics and eugenics in an agricultural context, 1902-13. Social Studies of Science, 13, 2, p. 163-204, 1983.

Laughlin, H. H. Eugenical sterilization in the United States. Chicago: Psychopathic Laboratory of the Municipal Court of Chicago, 1922.

Lorimer, D. A. Race, science and culture: historical continuities and discontinuities, 1850-1914. In: WeST, S. (Ed.). The Victorians and race. Aldershot: Ashgate, 1996. p. 12-33.

Madureira, N. L. A estatística do corpo: antropologia física e antropometria na alvorada do século xx. Etnográfica, 7, 2, p. 283-3o3, 2003. Disponível em: <http://ceas.iscte.pt/etnografica/docs/vol_o7/N2/ Vol_vii_N2_283-3o4.pdf >. Acesso em: 21 set. 2013.

Magnello, M. E. The non-correlation of biometrics and eugenics: rival forms of laboratory work in Karl Pearson's career at University College London. History of Science, 37, 116, p. 123-50, 1999.

MaYr, E. O desenvolvimento do pensamento biológico. Tradução I. Martinazzo.Brasília: Editora UnB, 1998.

Mehler, B. A. A history of the American Eugenics Society, 1921-1940. Urbana, 1988. Tese (Doutorado em História). University of Illinois. Disponível em: 〈http://www.ferris.edu/isar/dissertation/intro.pdf〉. Acesso em: 27 set. 2013.

Ortiz, R. A sociologia de Pierre Bourdieu. São Paulo: Olho d’Água, 2005.

Osвorn, F H. The future of human heredity: an introduction to eugenics in modern society. New York: Wybright \& Talley, 1968.

PAuL, D. B. Controlling human heredity. Atlantic Highlands, NJ: Humanities Press International, Humanity Books, 1995 .

Pearl, R. The First International Eugenics Congress. Science, new series, 36, 926, p. 395-6, 1912.

Рiснот, A. Hérédité et évolution: l'inné et l'acquis en biologie. Esprit, 222, p. 7-26, 1996.

Reilly, P. R. Involuntary sterilization in the United States: a surgical solution. The Quarterly Review of Biology, 62, 2, p. $15^{3-70,1987 .}$

Selden, S. Inheriting shame: the story of eugenics and racism in America. New York: Teachers College Press, 1999.

United States Suprem Court. Buck vs. Bell, 274, U. S. 200, 1927. Disponível em: <http://supreme.justia. $\mathrm{com} /$ cases/federal/us/274/200/case.html>. Acesso em: 27 set. 2013.

Waters, M. C \& Esch bach, K. Immigration and ethnic and racial inequality in the United States. Annual Review of Sociology, 21, p. 419-4,6, 1995 . 
WeIss, S. F. The race hygiene movement in Germany. Osíris, série 2, 3, p. 193-236, 1987.

Winfield, A. G. Eugenics and education: implications of ideology, memory, and history for education in the United States. Raleigh, NC, 2004. Tese (Doutorado em Filosofia). Graduate Faculty of North Carolina State. Disponível em: 〈http://repository.lib.ncsu.edu/ir/bitstream/184,0.16/4234/1/etd.pdf >. Acesso em: 21 set. 2013. 